\title{
Metrology for $\mathrm{pH}$ Measurements in Brackish Waters-Part 1: Extending Electrochemical $\mathrm{pH}_{\mathrm{T}}$ Measurements of TRIS Buffers to Salinities 5-20
}

\begin{abstract}
Jens D. Müller ${ }^{1}$, Frank Bastkowski ${ }^{2 *}$, Beatrice Sander ${ }^{2}$, Steffen Seitz ${ }^{2}$, David R. Turner ${ }^{3}$, Andrew G. Dickson ${ }^{4}$ and Gregor Rehder ${ }^{1}$

' Department of Marine Chemistry, Leibniz Institute for Baltic Sea Research Warnemünde, Rostock, Germany, ${ }^{2}$ Department of Physical Chemistry, Physikalisch-Technische Bundesanstalt, Braunschweig, Germany, ${ }^{3}$ Department of Marine Sciences, University of Gothenburg, Gothenburg, Sweden, ${ }^{4}$ Marine Physical Laboratory, Scripps Institution of Oceanography, University of California, San Diego, La Jolla, CA, United States
\end{abstract}

\section{OPEN ACCESS}

Edited by:

Eric 'Pieter Achterberg, GEOMAR Helmholtz-Zentrum für Ozeanforschung Kiel, Germany

Reviewed by: Marta Plavsic, Rudjer Boskovic Institute, Croatia

Stathys Papadimitriou, National Oceanography Centre Southampton, United Kingdom

Socratis Loucaides, National Oceanography Centre Southampton, United Kingdom

*Correspondence: Frank Bastkowski frank.bastkowski@ptb.de

Specialty section: This article was submitted to Marine Biogeochemistry, a section of the journal Frontiers in Marine Science

Received: 26 January 2018 Accepted: 03 May 2018 Published: 10 July 2018

Citation:

Müller JD, Bastkowski F, Sander B, Seitz $S$, Turner DR, Dickson AG and Rehder $\mathrm{G}$ (2018) Metrology for $\mathrm{pH}$ Measurements in Brackish Waters-Part 1: Extending Electrochemical $\mathrm{pH}_{T}$ Measurements of TRIS Buffers to Salinities 5-20.

Front. Mar. Sci. 5:176. doi: 10.3389/fmars.2018.00176
Harned cell $\mathrm{pH}_{\mathrm{T}}$ measurements were performed on 2-amino-2-hydroxymethyl-1,3-propanediol (TRIS) buffered artificial seawater solutions in the salinity range 5-20, at three equimolal buffer concentrations $(0.01,0.025$, $0.04 \mathrm{~mol} \cdot \mathrm{kg}-\mathrm{H}_{2} \mathrm{O}^{-1}$ ), and in the temperature range $278.15-318.15 \mathrm{~K}$. Measurement uncertainties were assigned to the $\mathrm{pH}_{\mathrm{T}}$ values of the buffer solutions and ranged from 0.002 to 0.004 over the investigated salinity and temperature ranges. The $\mathrm{pH}_{\mathrm{T}}$ values were combined with previous results from literature covering salinities from 20 to 40 . A model function expressing $\mathrm{pH}_{\mathrm{T}}$ as a function of salinity, temperature and TRIS/TRIS. $\mathrm{H}^{+}$ molality was fitted to the combined data set. The results can be used to reliably calibrate $\mathrm{pH}$ instruments traceable to primary standards and over the salinity range 5-40, in particular, covering the low salinity range of brackish water for the first time. At salinities 5-20 and 35, the measured dependence of $\mathrm{pH}_{\mathrm{T}}$ on the TRIS/TRIS. $\mathrm{H}^{+}$molality enables extrapolation of quantities calibrated against the $\mathrm{pH}_{\mathrm{T}}$ values, e.g., the dissociation constants of $\mathrm{pH}$ indicator dyes, to be extrapolated to zero TRIS molality. Extrapolated quantities then refer to pure synthetic seawater conditions and define a true hydrogen ion concentration scale in seawater media.

Keywords: Harned cell, traceability, primary standard, TRIS, pH, total scale, brackish water, seawater

\section{INTRODUCTION}

Changes in seawater $\mathrm{pH}$ are linked to changes in the concentration of dissolved inorganic carbon and alkalinity. Precise and accurate $\mathrm{pH}$ measurements are therefore an ideal tool to investigate two processes of global importance: (i) Ocean acidification, caused by the uptake of anthropogenic carbon dioxide $\left(\mathrm{CO}_{2}\right)$ from the atmosphere (Le Quéré et al., 2016), can be directly traced by pH measurements in open ocean environments (Byrne et al., 2010). (ii) The investigation of biogeochemical transformations can be supported by $\mathrm{pH}$ measurements, as any production or mineralization of organic matter is inevitably coupled to the uptake and release of $\mathrm{CO}_{2}$.

In many brackish water systems, intense biogeochemical transformations cause pronounced $\mathrm{pH}$ fluctuations superimposed on long-term $\mathrm{pH}$ trends due to the uptake of anthropogenic $\mathrm{CO}_{2}$ 
(Hofmann et al., 2011). Accurate traceable and direct $\mathrm{pH}$ measurements are essential in deciphering the impact of both drivers. Furthermore, open ocean and brackish waters differ with respect to two characteristics of alkalinity, which underlines the need for accurate and traceable $\mathrm{pH}$ measurements in the latter waters. Firstly, alkalinity levels in brackish waters can change on time scales of ocean acidification. For example, Müller et al. (2016) reported an increase in alkalinity over the past two decades for the Baltic Sea, one of the world's largest estuarine systems, that significantly buffered the acidification caused by anthropogenic $\mathrm{CO}_{2}$ uptake. Consequently, acidification trends cannot reliably be predicted from changes in $\mathrm{pCO}_{2}$ as is the case in open ocean waters with stable alkalinity levels (Doney et al., 2009), but require direct pH measurements. Secondly, brackish waters are typically characterized by high loads of dissolved organic matter that contribute significantly to alkalinity, which results in erroneous results if alkalinity is used as an input parameter for $\mathrm{CO}_{2}$ system calculations (Kulinski et al., 2014). Under such conditions, accurate and precise $\mathrm{pH}$ measurements are extremely valuable for a complete determination of the $\mathrm{CO}_{2}$ system. It was shown that this can in principle be achieved by spectrophotometric $\mathrm{pH}$ measurements, because the methods work reliably even in the presence of high amounts of dissolved organic matter (Müller et al., 2018).

According to its definition on the activity scale, $\mathrm{pH}=$ $-\log _{10}\left(a_{\mathrm{H}^{+}}\right), \mathrm{pH}$ involves a single ion quantity and is as such immeasurable by any thermodynamically valid method (Buck et al., 2002). pH measurements according to the IUPAC recommendation require conventions which are only valid for ionic strength $\leq 0.1 \mathrm{~mol} \cdot \mathrm{kg}^{-1}$. For measurements in seawater with a higher ionic strength it is convenient to measure $\mathrm{pH}$ on scales that refer to the hydrogen ion concentration. The definition of such concentration scales requires the definition of a standard composition of seawater, because hydrogen ions are in equilibrium with other acid base components in seawater. $\mathrm{pH}_{\mathrm{T}}$, where the index $\mathrm{T}$ denotes the total $\mathrm{pH}$ scale, has become a widely accepted convention within the scientific community (Dickson et al., 2015). According to its definition, $\mathrm{pH}_{\mathrm{T}}=-\log _{10}\left\{\left[\mathrm{H}^{+}\right]\left(1+\frac{\left[\mathrm{SO}_{4}^{2-}\right]_{T}}{K_{\mathrm{HSO}_{4}^{-}}}\right)\right\}$, it accounts for the concentrations of both, the free hydrogen ions, $\left[\mathrm{H}^{+}\right]$, and hydrogen sulfate ions, expressed as the total sulfate concentration $\left[\mathrm{SO}_{4}^{2-}\right]_{T}$ divided by the dissociation constant of hydrogen sulfate $\mathrm{K}_{\mathrm{HSO}_{4}^{-}}$. The latter contribute to the acidity of the solution by the potential to transfer further hydrogen ions to other proton acceptors.

In order to assure comparability of $\mathrm{pH}_{\mathrm{T}}$ measurement results, internationally accepted primary $\mathrm{pH}_{\mathrm{T}}$ standards are essential. Currently the de facto standards are TRIS (2-amino2-hydroxymethyl-1,3-propanediol) buffered artificial seawater (ASW) solutions (DelValls and Dickson, 1998; Pratt, 2014) in the salinity $(\mathrm{S})$ range $20-40$, where $\mathrm{pH}_{\mathrm{T}}$ values have been measured using an electrochemical setup comprising Harned cells. This setup represents a primary method for $\mathrm{pH}$ measurements (Buck et al., 2002). In oceanographic practice, $\mathrm{pH}_{\mathrm{T}}$ is typically measured by other methods such as spectrophotometry (Clayton and Byrne, 1993; Liu et al., 2011) and Ion Selective Field Effect Transistor (ISFET) (Martz et al., 2010). The spectrophotometric $\mathrm{pH}_{\mathrm{T}}$ measurement relies on $\mathrm{pH}$ indicator dyes such as $\mathrm{m}$-Cresol Purple (mCP). Standard buffer solutions with well-defined, traceable $\mathrm{pH}_{\mathrm{T}}$ values are required for the physico-chemical characterization of the purified dyes. This characterization was previously achieved for the indicator $\mathrm{mCP}$ in the salinity range 20-40 and temperatures from 273.15 to $308.15 \mathrm{~K}$ (Liu et al., 2011), based on the TRIS buffer characterization by DelValls and Dickson (1998). Recently, similar standards were achieved for sea-ice brines with temperatures as low as the freezing point by a successive characterization of hypersaline TRIS buffers (Papadimitriou et al., 2016) and-based on those buffer solutions-the extended characterization of mCP (Loucaides et al., 2017).

Up to now, Harned cell measurements on TRIS buffered ASW solutions in the lower salinity range $(S<20)$ have not been made. Consequently, spectrophotometrically obtained $\mathrm{pH}_{\mathrm{T}}$ values in this salinity range were not traceable to a primary $\mathrm{pH}_{\mathrm{T}}$ standard. Mosley et al. (2004) provided an interim solution by interpolating the $\mathrm{pH}_{\mathrm{T}}$ values of TRIS buffered ASW solutions for the salinity range $0-20$. The interpolation was based on the results for $S=20-40$ of DelValls and Dickson (1998) and for TRIS in pure water by Bates and Hetzer (1961). Although the solutions of Bates and Hetzer (1961) contained no other salts, (Mosley et al., 2004) interpreted the buffer ionic strength as salinity, leading to questionable accuracy. Moreover, non-purified dye was used for the $\mathrm{mCP}$ characterization and measurements were conducted only at 298.15 K (Mosley et al., 2004). Consequently, spectrophotometric $\mathrm{pH}_{\mathrm{T}}$ measurements in brackish waters with salinity below 20 were not traceable to a primary $\mathrm{pH}_{\mathrm{T}}$ standard and results were subject to an unknown degree of measurement uncertainty.

To fill this gap, we present Harned cell $\mathrm{pH}_{\mathrm{T}}$ measurement results in the salinity range 5-20 and, in addition, at 35 for assessment of consistency with the previous results of DelValls and Dickson (1998) and Pratt (2014). In particular, we discuss issues of buffer solution preparation in the low salinity range, which differs significantly from that in the upper salinity range and affects $\mathrm{pH}_{\mathrm{T}}$ measurements. Measurements were performed in the temperature range 278.15 to $318.15 \mathrm{~K}$. All buffer solutions were prepared at three equimolal concentrations of TRIS/TRIS. $\mathrm{H}^{+}$, which allows extrapolation of calibration parameters determined in these solutions to pure artificial seawater conditions as recommended by Nemzer and Dickson (2005). We combined our results with those of DelValls and Dickson (1998) to derive a consistent $\mathrm{pH}_{\mathrm{T}}$ model for the salinity range 5-40, which is a prerequisite to comparing $\mathrm{pH}_{\mathrm{T}}$ values measured in ocean and brackish waters.

\section{MATERIALS AND METHODS}

\section{Scope and Concept}

We prepared and analyzed TRIS buffered ASW solutions (ASW/TRIS-HCl) with salinities $S=5,10,15,20$, and 35 . Preparing low-saline buffer solutions for subsequent calibration 


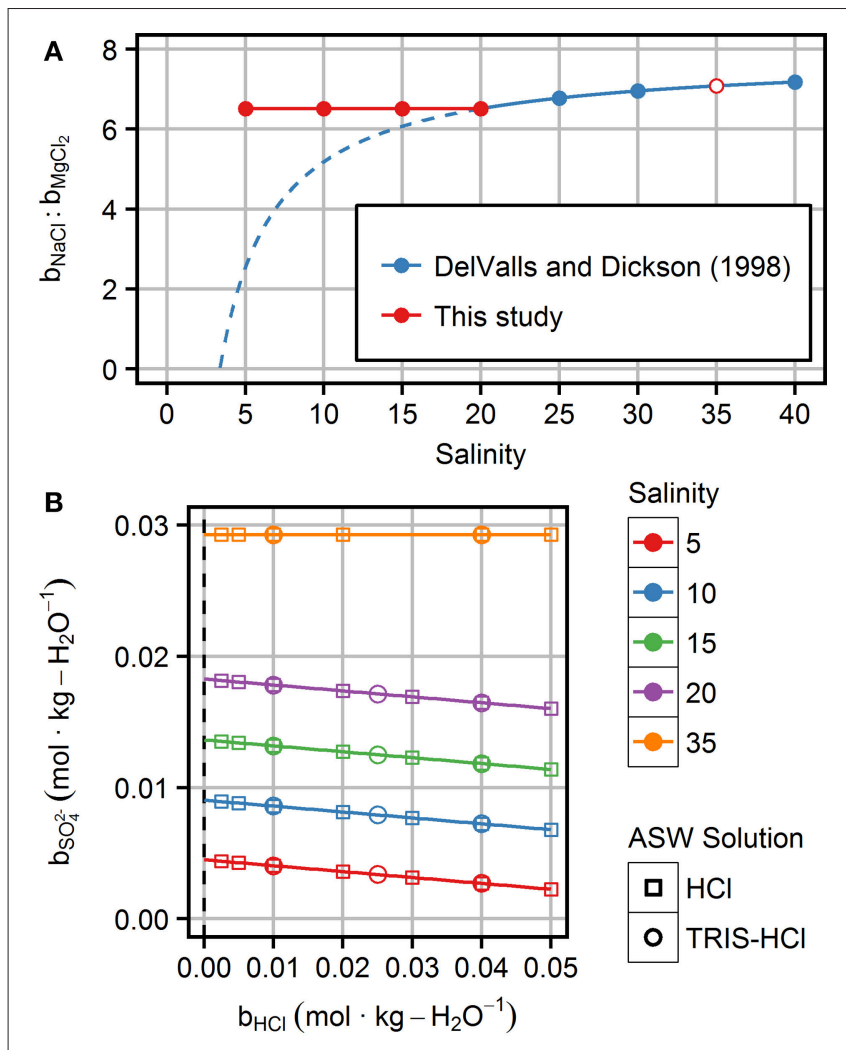

FIGURE 1 | Characteristics of artificial seawater solutions prepared in this study: (A) Cation composition represented by $b_{\mathrm{NaCl}}: b_{\mathrm{MgCl}_{2}}$ molality ratios for ASW solutions with a $\mathrm{HCl}$ molality of $0.04 \mathrm{~mol} \cdot \mathrm{kg}-\mathrm{H}_{2} \mathrm{O}^{-1}$. The cation ratios as prepared in this study (red) are compared to those proposed by DelValls and Dickson (1998) - actually prepared: blue circles and solid line; recipe hypothetically applied for lower salinities: dashed blue line. (B) Sulfate molality, $b_{\mathrm{SO}_{4}^{2-}}$, as a function of $\mathrm{HCl}$ molality and salinity. Squares represent $\mathrm{HCl}$ solutions in ASW to measure the standard potential of the Harned cell, $E^{\star 0}$. Circles indicate the three investigated TRIS/TRIS. $\mathrm{H}^{+}$molalities.

of $\mathrm{pH}$ instruments includes a general problem: $\mathrm{HCl}$ added contribute significantly to the ionic strength of the buffer solution. An equivalent amount of salt components of the ASW matrix has to be removed to ensure constant ionic strength. Consequently, the solution composition used for the calibration of any $\mathrm{pH}$ instrument differs from the seawater to be analyzed. For a classical equimolal TRIS/TRIS. $\mathrm{H}^{+}$buffer with a molality of $0.04 \mathrm{~mol} \cdot \mathrm{kg}-\mathrm{H}_{2} \mathrm{O}^{-1}$ (DelValls and Dickson, 1998), the ionic strength contribution ranges from 5 to $10 \%$ for salinities of 40-20. The impact of this ionic strength contribution on the determination of the dissociation constant of $\mathrm{mCP}$ has not yet been assessed. Even though it might be negligible within the overall uncertainty of seawater $\mathrm{pH}_{\mathrm{T}}$ measurements at salinities above 20, this assumption is critical at lower salinities since the contribution of the buffer substance increases with decreasing salinity. This problem is inevitable and counteracting it by reducing the concentration of the buffer component comes at the cost of reduced buffer stability. To account for this problem, equimolal buffer consisting of TRIS and protonated TRIS
TABLE 1 | Reference solution composition computed according to DelValls and Dickson (1998) for $S=20$ and $b_{\mathrm{HCl}}=0.04 \mathrm{~mol} \cdot \mathrm{kg}-\mathrm{H}_{2} \mathrm{O}^{-1}$.

\begin{tabular}{ll}
\hline Component & Molality $\left(\mathbf{m o l} \cdot \mathbf{k g} \cdot \mathbf{H}_{\mathbf{2}} \mathbf{O}^{-\mathbf{1}}\right)$ \\
\hline $\mathrm{NaCl}$ & 0.20061 \\
$\mathrm{Na}_{2} \mathrm{SO}_{4}$ & 0.01647 \\
$\mathrm{KCl}$ & 0.00595 \\
$\mathrm{MgCl}_{2}$ & 0.03080 \\
$\mathrm{CaCl}_{2}$ & 0.00605 \\
\hline
\end{tabular}

$\left(\mathrm{TRIS} \cdot \mathrm{H}^{+}\right.$) each at molalities of $0.04,0.025$, and $0.01 \mathrm{~mol} \cdot \mathrm{kg}-$ $\mathrm{H}_{2} \mathrm{O}^{-1}$ were prepared and individual $\mathrm{pH}_{\mathrm{T}}$ values measured. This allows extrapolation of the measured quantities to zero TRIS/TRIS. $\mathrm{H}^{+}$molality (Müller and Rehder, 2018).

The relative composition of the salts $\left(\mathrm{NaCl}, \mathrm{MgCl}_{2}, \mathrm{Na}_{2} \mathrm{SO}_{4}\right.$, $\mathrm{CaCl}_{2}$, and $\mathrm{KCl}$ ) that form the ASW matrix is an associated problem. DelValls and Dickson (1998) computed the salt composition by first scaling a TRIS-free reference composition from $S=35$ to the target salinity. Afterwards, the amount of $\mathrm{NaCl}$ was reduced by the amount of $\mathrm{HCl}$ added to maintain the nominal ionic strength. If a specific $\mathrm{HCl}$ concentration, e.g., 0.04 $\mathrm{mol} \cdot \mathrm{kg}-\mathrm{H}_{2} \mathrm{O}^{-1}$, is adjusted, this approach implies changing the ratios between $\mathrm{Na}^{+}$and other cations at different salinities. For salinities of 20-40 those changes are small (Figure 1A). However, toward lower salinities the differences in the cation ratios become more pronounced. At a salinity of $\sim 4, \mathrm{NaCl}$ would be entirely replaced by $\mathrm{HCl}$ when preparing solutions according to DelValls and Dickson (1998). Therefore, only our buffers at $S=35$ and the buffer at $S=20$ with equimolal TRIS/TRIS $\cdot \mathrm{H}^{+}$molality of $0.04 \mathrm{~mol} \cdot \mathrm{kg}-\mathrm{H}_{2} \mathrm{O}^{-1}$ have been prepared according to the recipe of DelValls and Dickson (1998) in order to achieve best comparability to previous studies. The recipe was modified to achieve constant ratios between the ASW salts for all other buffer solutions.

\section{Preparation of the TRIS- $\mathrm{HCl}$ and $\mathrm{HCl}$ Solutions in Artificial Seawater}

We have chosen the composition proposed by DelValls and Dickson (1998) for $S=20$ and $\mathrm{HCl}$ molality $b_{\mathrm{HCl}}=0.04 \mathrm{~mol} \cdot \mathrm{kg}$ $\mathrm{H}_{2} \mathrm{O}^{-1}$ as the reference composition of ASW (Table 1). Based on the reference composition at $S=20$, the concentrations of all ASW salts were varied proportionally to compensate for the $\mathrm{HCl}$ ionic strength contribution and achieve target salinities. This proportional variation of the molality $b$ of any salt component x $\left(\mathrm{NaCl}, \mathrm{MgCl}_{2}, \mathrm{Na}_{2} \mathrm{SO}_{4}, \mathrm{CaCl}_{2}\right.$, and $\left.\mathrm{KCl}\right)$ was computed as a function of $S$ and $b_{\mathrm{HCl}}$ according to:

$$
\begin{aligned}
& b_{\mathrm{X}}\left(S, b_{\mathrm{HCl}}\right)= \\
& \frac{I(S)-b_{\mathrm{HCl}}}{I(20)-0.04 \mathrm{~mol} \cdot \mathrm{kg}-\mathrm{H}_{2} \mathrm{O}^{-1}} \cdot b_{\mathrm{X}}\left(20,0.04 \mathrm{~mol} \cdot \mathrm{kg}-\mathrm{H}_{2} \mathrm{O}^{-1}\right)
\end{aligned}
$$

where $b_{\mathrm{HCl}}$ is the target molality of $\mathrm{HCl}$ in mol.kg- $\mathrm{H}_{2} \mathrm{O}^{-1}$ (which is identical to $\left.b_{\text {TRIS/TRIS. } H^{+}}\right), 0.04 \mathrm{~mol} \cdot \mathrm{kg}-\mathrm{H}_{2} \mathrm{O}^{-1}$ refers to $b_{\mathrm{HCl}}$ in the reference solution, $b_{\mathrm{x}}\left(20,0.04 \mathrm{~mol} \cdot \mathrm{kg}-\mathrm{H}_{2} \mathrm{O}^{-1}\right)$ is the molality of salt $\mathrm{x}$ in the reference solution summarized in Table $\mathbf{1}$, and I is 
the ionic strength calculated from the target salinity $S$ by:

$$
I(S)=\frac{19.919 \cdot S}{1000-1.00192 \cdot S}
$$

Based on the reference composition of ASW according to DelValls and Dickson (1998), Equation (2) achieves proportional scaling of ionic strength in moles per kg solution with salinity (nominator) and conversion to ionic strength in moles per $\mathrm{kg}$ water (denominator). Coefficients in Equation (2) are based on IUPAC 2013 atomic weights (Meija et al., 2016).

For measurements of $\mathrm{pH}_{\mathrm{T}}$ with Harned cells it is necessary to determine the standard potential of the silver-silver chloride $(\mathrm{Ag} \mid \mathrm{AgCl})$ electrodes. This can be achieved by measurements of a serial dilution of $\mathrm{HCl}$ in the respective solution (see chapter "Determination of $\mathrm{pH}_{\mathrm{T}}$ " below). Therefore, $\mathrm{HCl}$ solutions were prepared in ASW $(\mathrm{ASW} / \mathrm{HCl})$ at $b_{\mathrm{HCl}}$ of $0.0025,0.005,0.01$, $0.02,0.03,0.04$, and $0.05 \mathrm{~mol} \cdot \mathrm{kg}-\mathrm{H}_{2} \mathrm{O}^{-1}$ at each target salinity according to Equations (1) and (2) and Table 1.

Our preparation method of ASW/TRIS- $\mathrm{HCl}$ and ASW/HCl solutions has the following implications at salinities $\leq 20$ :

- Constant ratios of the ASW salt components at all salinities and $\mathrm{HCl}$ molalities, which is reflected in the $b_{\mathrm{NaCl}}: b_{\mathrm{MgCl}_{2}}$ ratio (Figure 1A).

- Variable chloride and sulfate molality at a given salinity, because more sulfate is removed at higher HCl (Figure 1B). This change in sulfate molality requires corrections (see "Sulfate correction for effective $E^{* \circ}$ values" below).

All solutions were prepared from stock solutions of $\mathrm{NaCl}$, $\mathrm{KCl}, \mathrm{CaCl}_{2}, \mathrm{MgCl}_{2}, \mathrm{Na}_{2} \mathrm{SO}_{4}$, TRIS and $\mathrm{HCl}$ that have been gravimetrically prepared with ultrapure water (see supplement). All weighings were performed using an analytical balance (Sartorius Genius) and were buoyancy corrected. The air density for buoyancy correction was calculated from the atmospheric conditions measured with a combined humidity and temperature sensor (Almemo) as well as a barometer (Setra Systems).

The various salts, $\mathrm{NaCl}, \mathrm{KCl}, \mathrm{CaCl}_{2}, \mathrm{MgCl}_{2}$ (originating from MV laboratories Inc., Frenchtown, NJ, USA and kindly supplied from METAS, Switzerland), and $\mathrm{Na}_{2} \mathrm{SO}_{4}$ (originating from Merck), were characterized by coulometric measurements (see supplement: Tables S1, S2.1). $\mathrm{NaCl}$ and $\mathrm{KCl}$ were dried at $383 \mathrm{~K}$ for $2 \mathrm{~h}$ before use. $\mathrm{CaCl}_{2}$ and $\mathrm{MgCl}_{2}$ are hygroscopic. Hence, stock solutions were prepared and characterized using ion chromatography (see supplement: Table S2.1). TRIS was purchased from NIST (SRM 723e). No losses of TRIS weight on drying over magnesium perchlorate could be detected in the range of weighing uncertainty. The $\mathrm{HCl}$ stock solution was prepared from Titrisol ampoules (Merck). The $\mathrm{HCl}$ stock solution molality was assayed by potentiometric titration against the stock solution of TRIS SRM 723e (see supplement). The titration of the $\mathrm{HCl}$ against the TRIS stock solution ensures equimolal TRIS/TRIS $\cdot \mathrm{H}^{+}$ratios in the produced buffer solutions. All dilutions were carried out with ultrapure water obtained from a Milli-Q system. Actual salinities of the ASW/TRIS-HCl solutions were calculated from the actual ionic strength based on weighings according to Equation (2).

\section{Harned Cell Measurements}

The $\mathrm{pH}_{\mathrm{T}}$ values of the ASW/TRIS-HCl solutions were calculated from measured potentials using Harned cells (Harned and Owen, 1958), which consist of a platinum hydrogen electrode and an $\mathrm{Ag} \mid \mathrm{AgCl}$ reference electrode. Both electrodes are placed into a U-tube measurement cell. Both electrodes are in direct contact with the solution measured, i.e., there is no electrolyte bridge or a similar junction necessary to connect the electrodes electrically. The cells also comprise a unit for humidification of the hydrogen gas (see picture of the Harned measurement cell in Figure S1). The cell voltage was measured after temperature stabilization using a digital voltmeter (Agilent A3458) and corrected for the actual partial pressure of the hydrogen gas $\mathrm{p}_{\mathrm{H} 2}$ (Hills and Ives, 1951). Details of the Harned cell setup and the cell voltage correction are given in the supplement.

Measurements of the artificial seawater solutions containing TRIS-HCl were always measured in triplicate while artificial seawater solutions containing different $\mathrm{HCl}$ molalities were measured only once in most of the cases (see Tables S5.1, S5.2 in the Supplement).

\section{Determination of $\mathrm{pH}_{\mathbf{T}}$}

$\mathrm{pH}_{\mathrm{T}}$ is defined on an amount content basis (moles per kilogram solution). However, the electrochemical measurement of $\mathrm{pH}_{\mathrm{T}}$ is established via the molality-based expression of $\mathrm{pH}_{\mathrm{b}}$ (DelValls and Dickson, 1998) according to:

$$
\mathrm{pH}_{\mathrm{b}}=\frac{E_{\mathrm{ASW} / \mathrm{TRIS}-\mathrm{HCl}}-E^{* \circ}}{\frac{R T \ln 10}{F}}+\log _{10}\left(\frac{b_{\mathrm{Cl}^{-}}^{\circ}}{b}\right)
$$

with the electric Harned cell potential $E_{\text {ASW/TRIS-HCl }}$ of the buffered artificial seawater solution, the standard potential $E^{* \circ}$ of the $\mathrm{Ag} \mid \mathrm{AgCl}$ electrode in pure ASW of the same nominal salinity, the molality $b_{\mathrm{Cl}^{-}}$of chloride in the solution and the standard molality $b^{\circ}=1 \mathrm{~mol} \cdot \mathrm{kg}-\mathrm{H}_{2} \mathrm{O}^{-1}$. The expression of $\mathrm{pH}_{\mathrm{b}}$ in Equation (3) assumes that the activity coefficient of $\mathrm{HCl}$ in the buffer solution is the same as its trace value in the pure artificial seawater (see section Discussion).

$E^{* \circ}$ was determined at each salinity and temperature from measured potentials $\mathrm{E}_{\mathrm{ASW} / \mathrm{HCl}}$ of $7 \mathrm{ASW}$ solutions with $\mathrm{HCl}$ molalities ranging from 0.0025 to $0.05 \mathrm{~mol} \cdot \mathrm{kg}_{-} \mathrm{H}_{2} \mathrm{O}^{-1}$. Therefore, $E^{\prime}$ values were calculated from measured $E_{\mathrm{ASW} / \mathrm{HCl}}$ according to Equation (4):

$$
E^{\prime}=E_{\mathrm{ASW} / \mathrm{HCl}}+\frac{R T \ln 10}{F} \cdot \log _{10}\left(\frac{b_{\mathrm{HCl}} \cdot b_{\mathrm{Cl}^{-}}}{\left(b^{\circ}\right)^{2}}\right)
$$

with $b_{\mathrm{HCl}}$ the molality of $\mathrm{HCl}$. $E^{* \circ}$ was determined as the intercept at zero $\mathrm{HCl}$ molality of a second order polynomial fitted to $E^{\prime}$ as a function of $b_{\mathrm{HCl}}$.

The $\mathrm{pH}_{\mathrm{b}}$ value derived from Equation (3) is molality-based, while $\mathrm{pH}_{\mathrm{T}}$ is defined in terms of the amount content (moles per $\mathrm{kg}$ solution). Therefore, $\mathrm{pH}_{\mathrm{T}}$ has to be calculated from $\mathrm{pH}_{\mathrm{b}}$ (DelValls and Dickson, 1998) according to:

$$
\mathrm{pH}_{\mathrm{T}}=\mathrm{pH}_{\mathrm{b}}-\log _{10}(1-0.00106 \cdot S)
$$




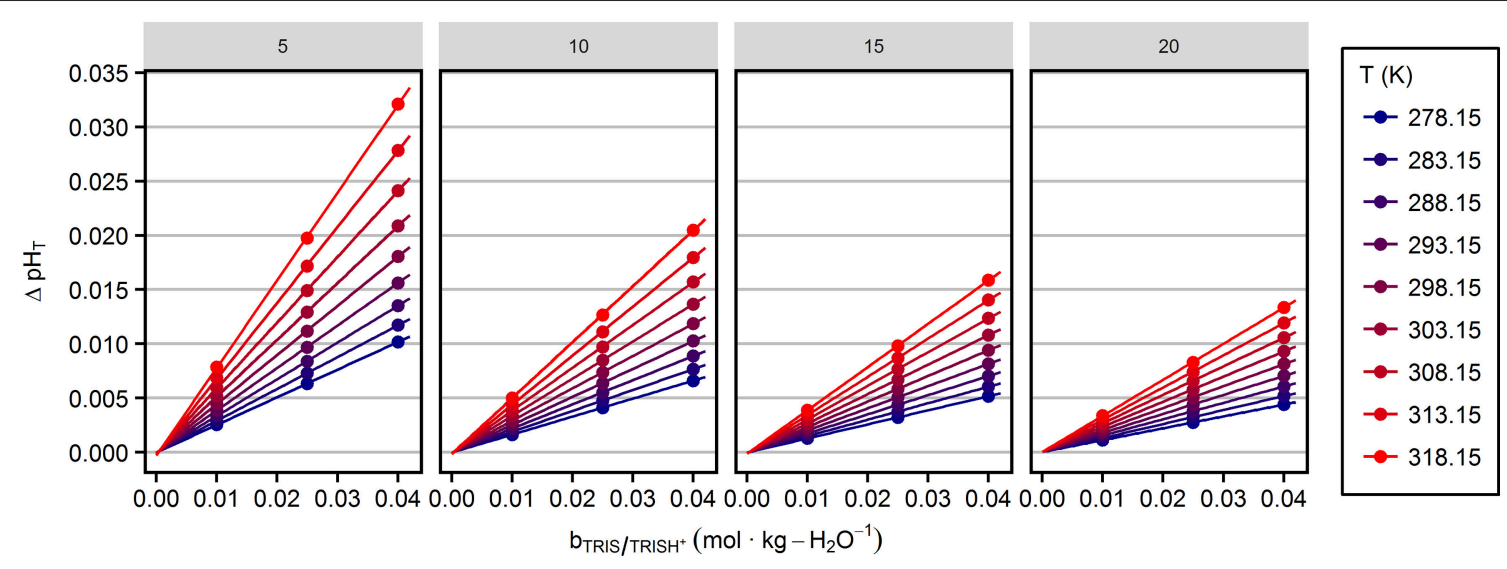

FIGURE 2 | Correction of $\mathrm{pH}_{\mathrm{T}}$ terms due to changes in the total sulfate concentration as a function of TRIS/TRIS. $\mathrm{H}^{+}$molality. Panels represent the four investigated salinities indicated at the top. Lines indicate the linear behavior at various temperatures.

where the term $1-0.00106 \cdot S$ expresses the relation between salinity and the water content of the pure ASW solution, $\omega_{\mathrm{H}_{2} \mathrm{O}}$. The latter is defined as mass water per mass solution (see section Discussion).

Twelve Harned cells have been used to measure the potential of 12 solutions simultaneously to reduce measurement time. Measurements of $\mathrm{ASW} / \mathrm{HCl}$ solution to determine $E^{* \circ}$ were not carried out in the same measurement run as the potential measurements of the ASW/TRIS- $\mathrm{HCl}$ solutions for practical reasons. To ensure that the electrochemical properties of the $\mathrm{Ag} \mid \mathrm{AgCl}$ electrodes is, within the uncertainty limits, the same for all solutions, the potentials of these electrodes were measured against a master $\mathrm{Ag} \mid \mathrm{AgCl}$ electrode. The master electrode was always stored in $0.005 \mathrm{M}$ hydrochloric acid and was considered to be stable in potential with time. The comparison measurements of all electrodes against the master electrode were performed in the same $\mathrm{HCl}$ solution before each measurement run and found to differ not more than $85 \mu \mathrm{V}$, corresponding to around 0.0015 in terms of $\mathrm{pH}$.

The uncertainties of the measured $\mathrm{pH}_{\mathrm{T}}$ values were determined for all temperatures, salinities and TRIS/TRIS $\cdot \mathrm{H}^{+}$ molalities according to the Guide to the expression of uncertainty in measurement (https://www.bipm.org/en/publications/ guides/) using a Monte Carlo method in Mathematica (for details see Supplement) (ISO/IEC, 2008).

\section{Sulfate Correction for Effective $E^{* \circ}$ Values}

$E^{* \circ}$ of an $\mathrm{Ag} \mid \mathrm{AgCl}$ electrode that is immersed in artificial seawater containing sulfate can be expressed as (DelValls and Dickson, 1998):

$$
E^{* \circ}=E^{\circ}-\frac{2 R T}{F} \ln \gamma_{ \pm}(\mathrm{HCl})+\frac{R T}{F} \ln \left(1+\frac{b_{\mathrm{SO}_{4}^{2-}, \mathrm{T}}}{K_{\mathrm{HSO}_{4}^{-}}}\right)
$$

where $E^{\circ}$ is the potential of the Harned cell under standard conditions, $\gamma_{ \pm}(\mathrm{HCl})$ is the trace activity coefficient of $\mathrm{HCl}$ in ASW, $b_{\mathrm{SO}_{4}^{2-}, \mathrm{T}}$ is the total sulfate molality and $K_{\mathrm{HSO}_{4}^{-}}$is the limiting molality quotient for hydrogen sulfate in artificial seawater medium.

It is assumed that $E^{* \circ}$, determined at a particular salinity and temperature, remains unchanged if some of the artificial seawater salts are replaced with TRIS- $\mathrm{HCl}$ such that the ionic strength is unchanged. However, in this study the TRIS-HCl addition was compensated by a proportional reduction of all ASW salts to keep the ratios of cations constant. Consequently, the sulfate concentration was also reduced. The change in sulfate concentration requires a correction so that the effective $E^{* \circ}$ corresponds to the respective ASW/TRIS-HCl solutions $\left(E^{* \circ}(\mathrm{ASW} / \mathrm{TRIS}-\mathrm{HCl})\right)$ and not to the infinite dilution of $\mathrm{HCl}$ solutions to pure ASW condition $\left(E^{*}(\mathrm{ASW})\right)$. According to Equation (3) the required correction can be expressed as:

$$
\Delta \mathrm{pH}_{\mathrm{T}}=\frac{F}{R T \ln 10}\left(E^{* \circ}(\text { ASW })-E^{* \circ}(\text { ASW } / \text { TRIS }-\mathrm{HCl})\right)
$$

$E^{* \circ}(\mathrm{ASW})$ and $E^{* \circ}$ (ASW/TRIS-HCl) in Equation (7) can be expressed by applying Equation (6), where $b_{\mathrm{SO}_{4}^{2-}, \mathrm{T}}$ is replaced by $b_{\mathrm{SO}_{4}^{2-}, \mathrm{T}}(A S W)$ and $b_{\mathrm{SO}_{4}^{2-}, \mathrm{T}}(\mathrm{ASW} / \mathrm{TRIS}-\mathrm{HCl})$, respectively. The former describes the sulfate molality in pure ASW and the latter describes the sulfate molality in ASW containing TRIS-HCl. $\mathrm{K}_{\mathrm{HSO}_{4}^{-}}$is assumed constant for a given temperature and salinity according to Dickson (1990). Thus,

$$
\begin{aligned}
\Delta \mathrm{pH}_{\mathrm{T}}= & \log _{10}\left(1+\frac{b_{\mathrm{SO}_{4}^{2-}, \mathrm{T}}(\mathrm{ASW})}{K_{\mathrm{HSO}_{4}^{-}}}\right) \\
& -\log _{10}\left(1+\frac{b_{\mathrm{SO}_{4}^{2-}, \mathrm{T}}(\mathrm{ASW} / \mathrm{TRIS}-\mathrm{HCl})}{K_{\mathrm{HSO}_{4}^{-}}}\right)
\end{aligned}
$$

The values of $\Delta \mathrm{pH}_{\mathrm{T}}$ calculated for the solution compositions of this study are displayed in Figure 2 and referred to as sulfate corrections hereafter. This correction does not account for any changes in the activity coefficients implicit in Equation 6 (see section Discussion). 
TABLE 2 | Coefficients for the $\mathrm{pH}_{\mathrm{T}}$ model (Equation 10). Test value: $\mathrm{pH}_{\mathrm{T}}=$ 8.0703 at $S=20, T=298.15 \mathrm{~K}$, and $b_{\text {TRIS } / \text { TRIS } \cdot \mathrm{H}^{+}}=\mathrm{mol} \cdot \mathrm{kg}-\mathrm{H}_{2} \mathrm{O}^{-1}$.

\begin{tabular}{|c|c|}
\hline Coefficient & Value \\
\hline a & -327.3307 \\
\hline$b_{1}$ & -2.400270 \\
\hline$b_{2}$ & $8.124630 \cdot 10^{-2}$ \\
\hline$b_{3}$ & $-9.635344 \cdot 10^{-4}$ \\
\hline$c_{1}$ & $-9.103207 \cdot 10^{-2}$ \\
\hline$c_{2}$ & $-1.963311 \cdot 10^{-3}$ \\
\hline$c_{3}$ & $6.430229 \cdot 10^{-5}$ \\
\hline$c_{4}$ & $-7.510992 \cdot 10^{-7}$ \\
\hline$d_{1}$ & 56.92797 \\
\hline$d_{2}$ & $5.235889 \cdot 10^{-1}$ \\
\hline$d_{3}$ & $-1.7602 \cdot 10^{-2}$ \\
\hline$d_{4}$ & $2.082387 \cdot 10^{-4}$ \\
\hline e & 11382.97 \\
\hline$f_{1}$ & -2.417045 \\
\hline$f_{2}$ & $7.645221 \cdot 10^{-2}$ \\
\hline$f_{3}$ & $1.122392 \cdot 10^{-2}$ \\
\hline$f_{4}$ & $-3.248381 \cdot 10^{-4}$ \\
\hline$g_{1}$ & -4.161537 \\
\hline$g_{2}$ & $6.143395 \cdot 10^{-2}$ \\
\hline
\end{tabular}

\section{Fitting Combined $\mathrm{pH}_{\mathrm{T}}$ Results for the Salinity Range 5-40}

In order to derive a common expression of $\mathrm{pH}_{\mathrm{T}}$ as a function of salinity, temperature and TRIS/TRIS. $\mathrm{H}^{+}$molality over the largest range of conditions, the sulfate-corrected $\mathrm{pH}_{\mathrm{T}}$ data from this study in the salinity range 5-20 were combined with previous $\mathrm{pH}_{\mathrm{T}}$ data in the salinity range 20-40. The latter were calculated from potentials given in Table 2 of DelValls and Dickson (1998) and corresponding $E^{* \circ}$ values from Dickson (1990) according to Equations (3) and (5). Only measurements in the temperature range investigated in this study $(278.15-318.15 \mathrm{~K})$ were included in the combined data set.

The following expression of $\mathrm{pH}_{\mathrm{T}}$ as a function (f) of $S, T$ and $b_{\text {TRIS/TRIS. }} \mathrm{H}^{+}$was specified as a full model and fitted to the combined data set:

$$
\begin{aligned}
\mathrm{pH}_{\mathrm{T}} & =f\left\{\left[\left(1+S+S^{2}+S^{3}\right) \cdot\left(1+T+\ln (T)+\frac{1}{T}\right)\right]\right. \\
& \left.+\left[\left(b_{\text {TRIS } / \text { TRIS } \cdot \mathrm{H}^{+}}+b_{\text {TRIS/TRIS }}^{2} \mathrm{H}^{+}\right) \cdot(1+S+T+S \cdot T)\right]\right\}
\end{aligned}
$$

The first part of this full model includes all combinations of the terms of a third order salinity polynomial with the terms of the physico-chemical expression of the temperature dependence of dissociation constants. This first part of Equation (9) deviates from the model fitted by DelValls and Dickson in their Equation (18) only by the higher order of the salinity polynomial. The second part of Equation (9) accounts for the dependence of $\mathrm{pH}_{\mathrm{T}}$ on the TRIS/TRIS $\cdot \mathrm{H}^{+}$molality. The total number of terms of the full model given in Equation (9) is 24.

The fit of the full model was obtained by generalized linear modeling with the "stats" package of the statistical programming language " $\mathrm{R}$ " (R Core Team, 2014). The model was fitted to the mean $\mathrm{pH}_{\mathrm{T}}$ values at each combination of target salinity, temperature, and TRIS/TRIS $\cdot \mathrm{H}^{+}$molality. Mean $\mathrm{pH}_{\mathrm{T}}$ values were weighted by the respective standard measurement uncertainty (Table S6) as $1 / u\left(\mathrm{pH}_{\mathrm{T}}\right)^{2}$. The temperature dependency of measurement uncertainty found in this study at salinities 20 and 35 was fitted with a linear model and the same uncertainty was assigned to the data of DelValls and Dickson (1998). After fitting the full model (Equation 9), insignificant terms were removed by stepwise variable selection in both directions based on the Akaike information criterion. The removal of insignificant terms was performed with the "stepAIC" function from the R package "MASS," and resulted in an expression with 19 terms given below in Equation (10).

\section{RESULTS}

\section{$\mathrm{pH}_{\mathrm{T}}$ of TRIS Buffers}

The $\mathrm{pH}_{\mathrm{T}}$ values of the equimolal TRIS buffered ASW solutions at salinities $5,10,15,20$, and 35 , temperatures from 278.15 to $318.15 \mathrm{~K}$ in intervals of $5 \mathrm{~K}$, as well as equimolal TRIS/TRIS. $\mathrm{H}^{+}$ molalities $0.04,0.025$, and $0.01 \mathrm{~mol} \cdot \mathrm{kg}-\mathrm{H}_{2} \mathrm{O}^{-1}$ are given in Table $\mathrm{S} 6$, the corresponding electric potentials of all solutions measured are given in Table S5.1 in the Supplemental Material.

Figure 3 shows mean $\mathrm{pH}_{\mathrm{T}}$ values (triplicate measurements) of ASW/TRIS-HCl solutions as a function of temperature $(278.15-318.15 \mathrm{~K})$, for salinities $5,10,15$, and 20 and at equimolal TRIS/TRIS. $\mathrm{H}^{+}$molality $0.04 \mathrm{~mol} \cdot \mathrm{kg}-\mathrm{H}_{2} \mathrm{O}^{-1} \cdot \mathrm{pH}_{\mathrm{T}}$ decreased almost linearly from around 8.7 to 7.5 with increasing temperature (around $-0.03 \mathrm{~K}^{-1}$ ). The investigation of the $\mathrm{pH}_{\mathrm{T}}$ dependence on temperature at other TRIS/TRIS. $\mathrm{H}^{+}$molalities showed no significant difference from the results shown in Figure 3.

Figure 4 displays in more detail the dependence of $\mathrm{pH}_{\mathrm{T}}$ on salinity and TRIS/TRIS. $\mathrm{H}^{+}$molality, including previous results from DelValls and Dickson (1998). $\mathrm{pH}_{\mathrm{T}}$ values shown in Figure 4 were corrected for minor difference $(<0.06 \mathrm{~K})$ between the actual measurement temperature (Table S6) and the target temperature indicated at the top of the panels to achieve a consistent presentation with the model results. At low temperatures $\mathrm{pH}_{\mathrm{T}}$ decreased with decreasing salinity. Toward higher temperatures, the lowest $\mathrm{pH}_{\mathrm{T}}$ values were found at intermediate salinities.

The expanded measurement uncertainty (coverage factor $k=$ 2) of $\mathrm{pH}_{\mathrm{T}}$ was found to range between 0.002 and 0.004 , with the highest uncertainties at salinity 5 and 15 (Figure S3). The uncertainty of $\mathrm{pH}_{\mathrm{T}}$ significantly increased with temperature at salinity 5 (Figure S3), whereas the temperature dependence of the measurement uncertainty was much less pronounced at higher salinities.

It was found that the uncertainty of the $\mathrm{pH}_{\mathrm{T}}$ values was dominated by the uncertainty contributions of the standard potential of the silver-silver chloride electrodes, $E^{* \circ}$, with relative contributions of $55-95 \%$ (Figure S4). The determination of $E^{* \circ}$ 


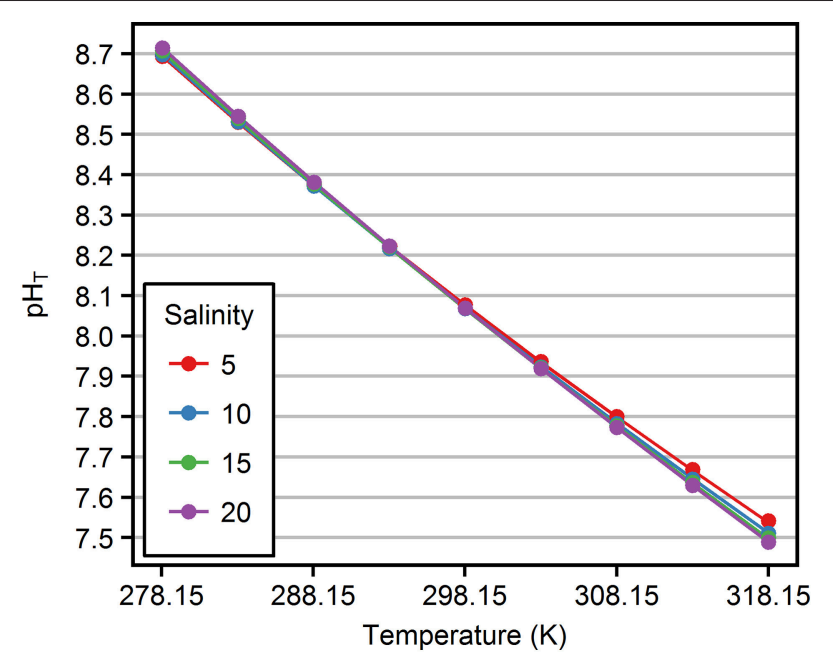

FIGURE $3 \mid \mathrm{pH}_{\mathrm{T}}$ values as a function of temperature. Circles represent mean measured $\mathrm{pH}_{\mathrm{T}}$ for $b_{\text {TRIS } / \text { TRIS. }} \mathrm{H}^{+}=0.04$ mol. $\mathrm{kg}-\mathrm{H}_{2} \mathrm{O}^{-1}$ and salinities 5-20 (color). Lines indicate the fitted $\mathrm{pH}_{\mathrm{T}}$ model at respective conditions. Measurement uncertainties are $<0.005$ and cannot be visualized due to the scaling of the $y$-axis.

was found to be sensitive to the extrapolation to zero $\mathrm{HCl}$ molality. The highest uncertainties of $E^{* \circ}$ were found at salinities 5 and 15 (Figure S4) resulting in the highest $\mathrm{pH}_{\mathrm{T}}$ uncertainties being found at these salinities (Figure S3).

The second most important uncertainty contribution was that of the cell potential measured in the buffer solutions,

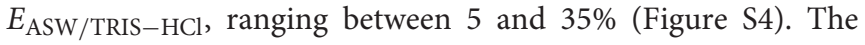
uncertainty of the measurement temperature $T$ contributed 1$4 \%$ and the molalities of the $\mathrm{NaCl}$, and $\mathrm{MgCl}_{2}$ stock solutions contributed in sum $1-7 \%$ to the $\mathrm{pH}_{\mathrm{T}}$ measurement uncertainty. All other contributions to the measurement uncertainty were $<1 \%$.

\section{$\mathrm{pH}_{\mathrm{T}}$ Model}

The $\mathrm{pH}_{\mathrm{T}}$ model fitted to the combined data set including results from this study and DelValls and Dickson (1998) is expressed in Equation (10). The parameters $T$ and $b_{\text {TRIS/TRIS. } \mathrm{H}^{+}}$ in Equation (10) were multiplied with $1 / \mathrm{K}$ and $1 / \mathrm{mol} \cdot \mathrm{kg}$ $\mathrm{H}_{2} \mathrm{O}^{-1}$, respectively, to derive dimensionless quantities. The corresponding dimensionless coefficients are given in Table 2.

$\mathrm{pH}_{\mathrm{T}}$ values predicted by this model are displayed along with mean $\mathrm{pH}_{\mathrm{T}}$ values in Figures 3 and 4. Residuals of triplicate $\mathrm{pH}_{\mathrm{T}}$ measurements from the model are shown in Figure 5, along with expanded measurement uncertainties (coverage factor $k=2$ ). No uncertainties are available for the results of DelValls and Dickson (1998). Therefore, we interpolated our uncertainties determined at salinity 20 and 35 to provide a rough estimate of the consistency between measurement results and residuals in the salinity range 20-40. The dependency of the measurement uncertainty on $b_{\text {TRIS/TRIS. }} \mathrm{H}^{+}$is negligible (Figure S3) and therefore not displayed in Figure 5. The residuals are within the range of the expanded measurement uncertainty, except for a few results at lowest TRIS/TRIS. $\mathrm{H}^{+}$molality and salinities 15 and 20 (Figure 5).

$$
\begin{aligned}
\mathrm{pH}_{\mathrm{T}}= & a+\left(b_{1} \cdot S+b_{2} \cdot S^{2}+b_{3} \cdot S^{3}\right) \\
& +\left(c_{1} \cdot T+c_{2} \cdot S \cdot T+c_{3} \cdot S^{2} \cdot T+c_{4} \cdot S^{3} \cdot T\right) \\
& +\left(d_{1} \cdot \ln (T)+d_{2} \cdot S \cdot \ln (T)+d_{3} \cdot S^{2} \cdot \ln (T)\right. \\
& \left.+d_{4} \cdot S^{3} \cdot \ln (T)\right)+\left(e \cdot \frac{1}{T}\right) \\
& +\left(f_{1} \cdot b_{\text {TRIS } / \text { TRIS }} \cdot H^{+}+f_{2} \cdot b_{\text {TRIS } / \text { TRIS } \cdot H^{+}} \cdot S\right. \\
& \left.+f_{3} \cdot b_{\text {TRIS/TRIS } \cdot H^{+}} \cdot T+f_{4} \cdot b_{\text {TRIS/TRIS } \cdot H^{+}} \cdot S \cdot T\right) \\
& +\left(g_{1} \cdot b_{\text {TRIS/TRIS } \cdot H^{+}}^{2}+g_{2} \cdot b_{\text {TRIS/TRIS } \cdot H^{+}}^{2} \cdot S\right)
\end{aligned}
$$

\section{DISCUSSION}

\section{Measurement Uncertainty and $\mathrm{pH}_{\mathrm{T}}$ Model}

The deviations of measured $\mathrm{pH}_{\mathrm{T}}$ values from the $\mathrm{pH}_{\mathrm{T}}$ model (Equation 10, Table 2) agree well with the range of the expanded measurement uncertainty (Figure 5), i.e., they are not significantly higher or lower. This indicates that the model represents the experimental results well, and does not overfit the data.

The deviations from the model reveal a minor salinitydependent pattern. In the salinity range 5-20, there is a tendency toward positive offsets at $S=15$ and negative offsets at $S=$ 20. As this tendency exists for the $\mathrm{pH}_{\mathrm{T}}$ of all TRIS/TRIS. $\mathrm{H}^{+}$ molalities and replicates, the patterns must have a common cause, which is likely to be the determination of the standard potential of the silver-silver chloride electrodes, $E^{* \circ}$. The determination of $E^{* \circ}$ represents the major contribution to the measurement uncertainty (55-95\%, Figure S4) and was only performed once for each combination of temperature and salinity. The uncertainty in the $E^{* \circ}$ determination is presumably related to the extrapolation to pure ASW conditions, which is especially sensitive to the $E^{\prime}$ measurements (Equation 4) at lowest $\mathrm{HCl}$ molalities. The model deviations reveal slightly positive offsets at $S=25$ and 30 , which is very similar to the patterns displayed in Figure 2B of DelValls and Dickson (1998).

No pronounced temperature-dependence of the residuals exists, except at salinity 5 and $b_{\text {TRIS/TRIS. } H^{+}}=0.04 \mathrm{~mol} \cdot \mathrm{kg}$ $\mathrm{H}_{2} \mathrm{O}^{-1}$, where a positive offset increases to a maximum of 0.004 at highest temperatures.

\section{Comparison to Previous Studies}

The highest deviation between $\mathrm{pH}_{\mathrm{T}}$ values measured in this study and by DelValls and Dickson (1998) across all temperatures, at salinities 20 and 35 , and $b_{\text {TRIS/TRIS. } \mathrm{H}^{+}}=0.04 \mathrm{~mol} \cdot \mathrm{kg}-\mathrm{H}_{2} \mathrm{O}^{-1}$ is 0.0025 at $S=35$ and $T=288.15 \mathrm{~K}$. The deviations are therefore within the extended measurement uncertainty of the method.

At salinities $\geq 20$, excellent agreement was found between our $\mathrm{pH}_{\mathrm{T}}$ model at $b_{\text {TRIS/TRIS. }} \mathrm{H}^{+}=0.04 \mathrm{~mol} \cdot \mathrm{kg}-\mathrm{H}_{2} \mathrm{O}^{-1}$ and the model defined in Equation (18) of DelValls and Dickson (1998). 


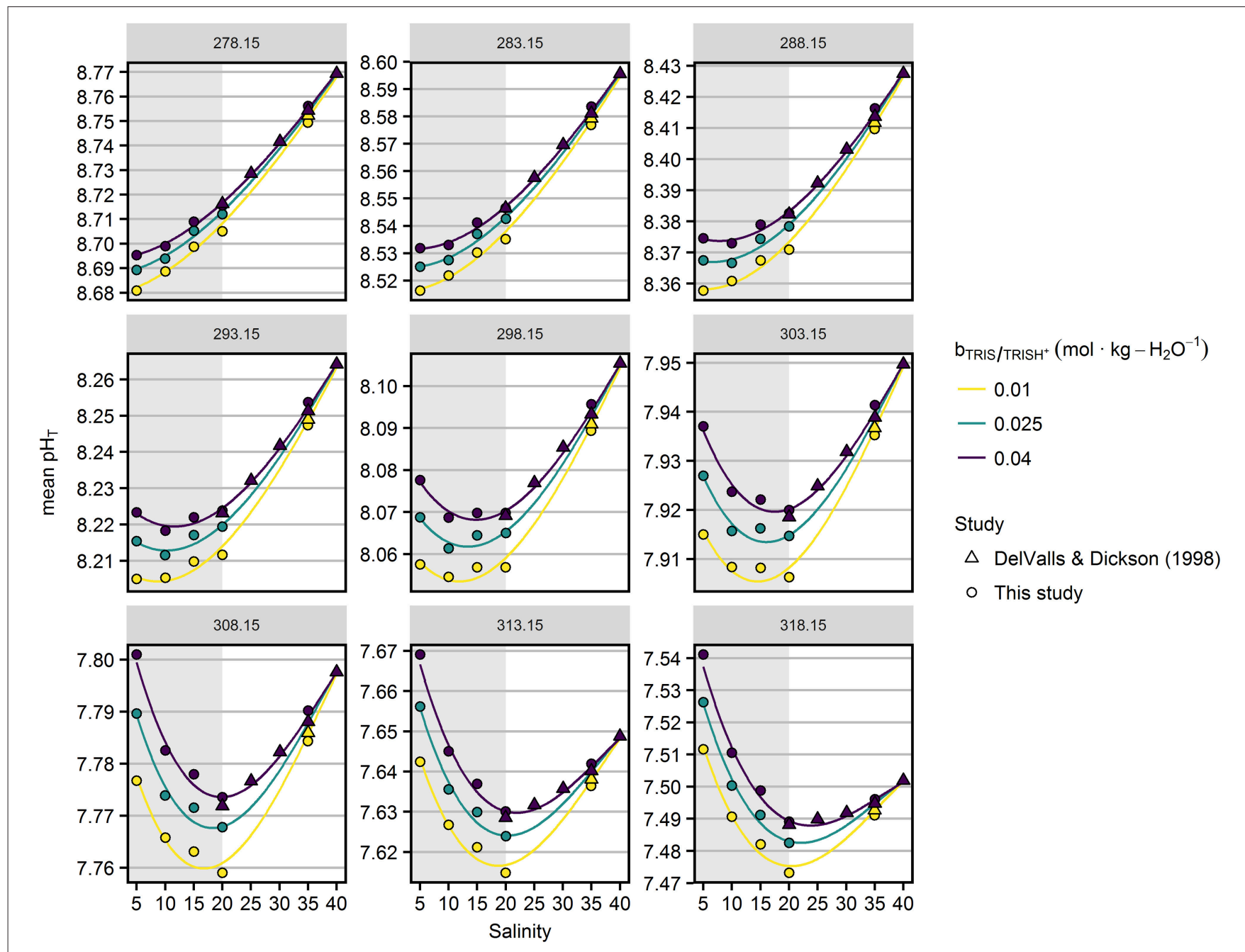

FIGURE 4 | Mean $\mathrm{pH}_{\mathrm{T}}$ values as a function of salinity (x-axis), temperatures (in $\mathrm{K}$, indicated at the top of the panels) and TRIS/TRIS. $\mathrm{H}^{+}$molalities (color). Circles represent results from this study highlighted by the gray area, triangles refer to DelValls and Dickson (1998). Lines represent the pH $\mathrm{T}$ model (Equation 10) fitted to the combined data set.

Differences are $<0.001$ for the entire salinity range $20-40$ and the temperature range 278.15-318.15 K (Figure S5). Within the range of the extended measurement uncertainty both models do not differ. The residuals from the model fitted in this study are larger than those presented in Figure 2 of DelValls and Dickson (1998), presumably a result of the larger range of salinities and the included dependency of $\mathrm{pH}_{\mathrm{T}}$ on TRIS/TRIS. $\mathrm{H}+$ molality in our model.

Our $\mathrm{pH}_{\mathrm{T}}$ model at $b_{\text {TRIS/TRIS. }} \mathrm{H}^{+}=0.04 \mathrm{~mol} \cdot \mathrm{kg}-\mathrm{H}_{2} \mathrm{O}^{-1}$ and $298.15 \mathrm{~K}$ and the model by Mosley et al. (2004) agree within 0.002 in the salinity range 20-40 (Figure S5), which is not surprising, because both models are based on the same results of DelValls and Dickson (1998). However, in the salinity range 5-20, where Mosley et al. (2004) interpolated the $\mathrm{pH}_{\mathrm{T}}$ of TRIS buffer solutions between the results of DelValls and Dickson (1998) for S>20 and the results of Bates and Hetzer (1961) in pure water, deviations increase up to 0.009 (Figure S5) and highlight the shortcomings of the interim solution.

\section{Correction of $E^{* \circ}$ for Changes in Sulfate Concentration and Activity Coefficients}

Changes in the sulfate concentration between pure ASW and ASW/TRIS-HCl solutions were corrected in this study according to Equation (8) (Figure 2). However, determined $E^{* \circ}$ values do not exactly correspond to the values required for $\mathrm{pH}_{\mathrm{T}}$ calculation in Equation (3), because changes in activity coefficients between pure ASW and ASW/TRIS-HCl solutions remain unaccounted for, namely:

(1) Changes in the value of $K_{\mathrm{HSO}_{4}^{-}}$arising from changes in the activity coefficients of $\mathrm{H}^{+}, \mathrm{SO}_{4}^{2-}$ and $\mathrm{HSO}_{4}^{-}$

(2) Changes in the activity coefficients of $\mathrm{H}^{+}$and $\mathrm{Cl}^{-}$

This limitation was previously discussed (e.g., Nemzer and Dickson, 2005; Dickson et al., 2015) and applies to all currently available experimental $\mathrm{pH}_{\mathrm{T}}$ measurements of TRIS buffered ASW solutions. The activity changes can only be corrected with 


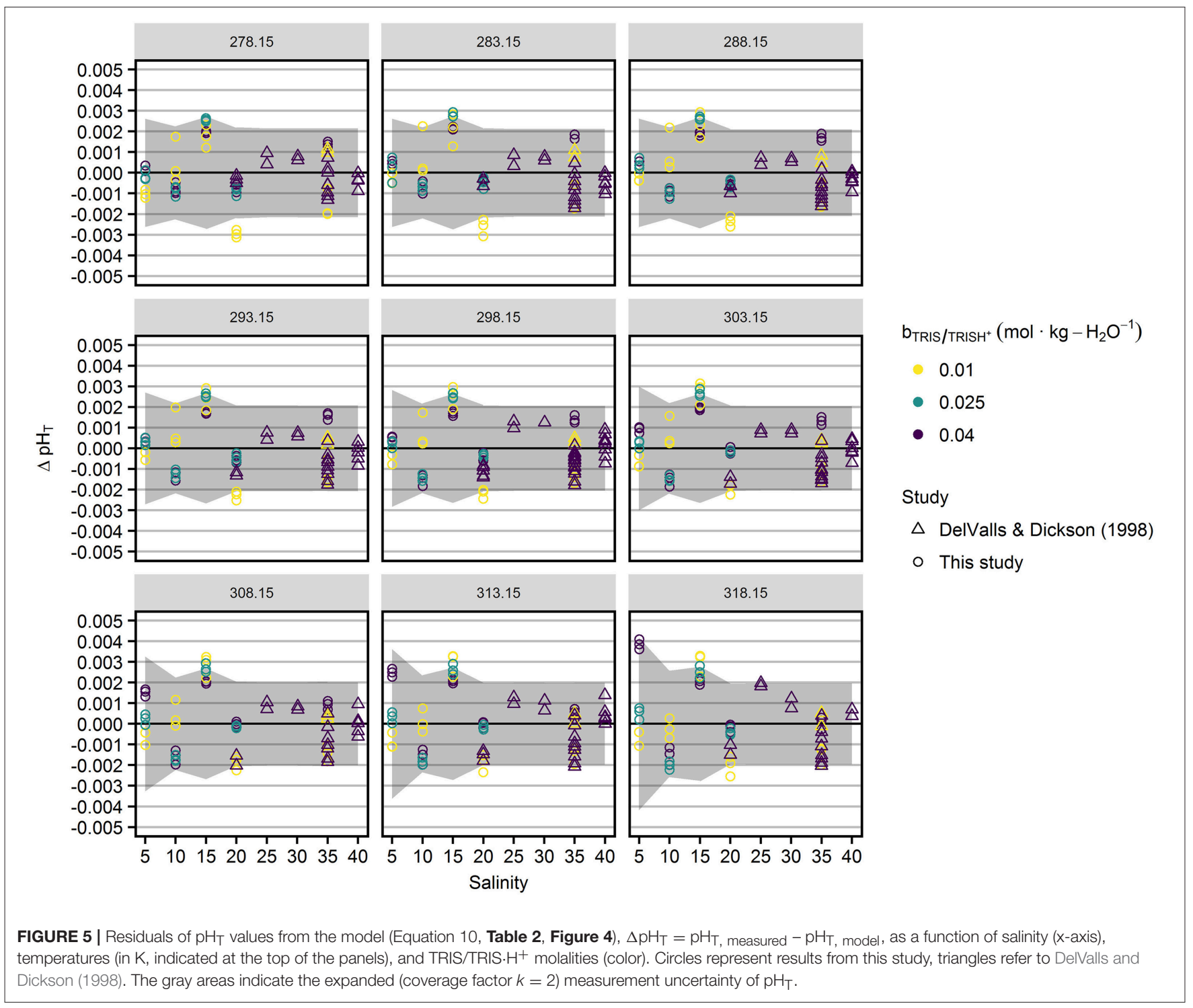

estimates from a speciation model. Gallego-Urrea and Turner (2017) have recently developed optimized Pitzer coefficients for TRIS in artificial seawater at $298.15 \mathrm{~K}$, using the artificial seawater model of Waters and Millero (2013). According to GallegoUrrea and Turner (2017), $\mathrm{pH}_{\mathrm{T}}$ correction terms, addressing the above mentioned effects (1) and (2), were calculated for the results of this study at $298.15 \mathrm{~K}$. Those $\Delta \mathrm{pH}_{\mathrm{T}}$ values from the speciation model differed from the applied sulfate corrections shown in Figure 2 by $<0.002$, indicating that changes in sulfate concentration dominate over the effect of changes in the activity coefficient.

However, the Pitzer coefficients for TRIS buffered ASW solutions are restricted to $298.15 \mathrm{~K}$ (Gallego-Urrea and Turner, 2017) due to scarcity of experimental data for other temperatures and can therefore not be applied consistently to the full temperature range covered in this study. The development of accurate Pitzer models for TRIS in artificial seawater over an extended temperature range is a main focus of the SCOR Working Group 145 "Modelling Chemical Speciation in Seawater to Meet Twenty first Century Needs” (http://marchemspec.org/).

It should be noted that the neglected effect of changes in activity coefficients does not impact the calibration of $\mathrm{pH}$ instruments, if those are performed at variable TRIS/TRIS. $\mathrm{H}^{+}$ molality and extrapolated to zero TRIS (see section: Calibration of $\mathrm{pH}$ instruments).

\section{Conversion Between $\mathrm{pH}_{\mathrm{b}}$ and $\mathrm{pH}_{\mathrm{T}}$}

The conversion of $\mathrm{pH}$ from the molality to the amount content scale (from $\mathrm{pH}_{\mathrm{b}}$ to $\mathrm{pH}_{\mathrm{T}}$ ) was calculated as the negative decadic logarithm of

$$
\omega_{\mathrm{H}_{2} \mathrm{O}}=1-0.00106 \cdot S
$$

according to DelValls and Dickson (1998). $\omega_{\mathrm{H}_{2} \mathrm{O}}$ represents the mass of water per mass solution and the given relationship 
between $\omega_{\mathrm{H}_{2} \mathrm{O}}$ and salinity refers to the composition of pure ASW. As pointed out by Pratt (2014), $\omega_{\mathrm{H}_{2} \mathrm{O}}$ in pure ASW is not exactly identical to $\omega_{\mathrm{H}_{2} \mathrm{O}}$ of the corresponding ASW/TRIS$\mathrm{HCl}$ solution, due to the difference of the total mass of solution per amount of water after replacing some of the ASW salts with TRIS/HCl. As a result, for solutions with a TRIS molality of $0.04 \mathrm{~mol} \cdot \mathrm{kg}-\mathrm{H}_{2} \mathrm{O}^{-1}$, the $\mathrm{pH}$ conversion based on the actually weighed buffer composition gives 0.003 and 0.004 higher $\mathrm{pH}_{\mathrm{T}}$ values at salinity 35 and 5, respectively, compared to those using Equation (4). Obviously, the conversion error decreases toward lower TRIS molality. To be consistent with the $\mathrm{pH}_{\mathrm{T}}$ results measured previously and to perform the $\mathrm{pH}_{\mathrm{T}}$-fit on a consistent database we have also used Equation (4) for the correction, even though we deem the conversion based on the actually weighed buffer composition more appropriate.

It should be noted that preliminary results obtained with the speciation model by Gallego-Urrea and Turner (2017) indicate that the correction of changes in activity coefficients between pure ASW and ASW/TRIS-HCl solutions, which has been neglected in this study due to the restriction of model results to $298.15 \mathrm{~K}$, is around -0.005 at $S=35$ and $b_{\text {TRIS/TRIS } \mathrm{H}^{+}}=$ $0.04 \mathrm{~mol} \cdot \mathrm{kg}-\mathrm{H}_{2} \mathrm{O}^{-1}$. This is in a similar order of magnitude, but with opposite sign compared to the effect of $\mathrm{pH}$ scale conversion according to Equation (11). Therefore, if adequate activity coefficients were available, superposition of the $\mathrm{pH}$ scale conversion using the actual buffer composition and the correction of changes in activity coefficients would be expected to provide $\mathrm{pH}_{\mathrm{T}}$ values that are within the range of uncertainties of the $\mathrm{pH}_{\mathrm{T}}$ value we have presented here.

In any case, the choice of the scale conversion does not impact the calibration of $\mathrm{pH}$ instruments, if they are performed at variable TRIS/TRIS. $\mathrm{H}^{+}$molality and extrapolated to zero TRIS (see chapter: Calibration of $\mathrm{pH}$ instruments).

\section{Calibration of pH Instruments}

We recommend the use of TRIS buffered ASW solutions as prepared in this study as $\mathrm{pH}_{\mathrm{T}}$-standards for future calibration of $\mathrm{pH}$ instruments in the salinity range 5-20, with assigned $\mathrm{pH}_{\mathrm{T}}$ values according to Equation (10) and Table 2. Moreover, this approach also allows for a consistent assignment of $\mathrm{pH}_{\mathrm{T}}$ values without discontinuity or significant differences to previous results in the salinity range $20-40$ when buffer solutions are prepared according to DelValls and Dickson (1998).

As discussed in the previous two chapters, the composition of TRIS buffer solutions differs from that of pure ASW. The contribution of TRIS-HCl to the total ionic strength increases toward lower salinities and:

(1) affects the $\mathrm{pH}_{\mathrm{T}}$ values of the buffer solutions (Figure 4),

(2) requires corrections of the $E^{* \circ}$ differences between pure ASW and ASW/TRIS-HCl,

(3) affects $\omega_{\mathrm{H}_{2} \mathrm{O}}$ and therefore the scale conversion between $\mathrm{pH}_{\mathrm{b}}$ and $\mathrm{pH}_{\mathrm{T}}$, and

(4) impacts the calibration quantity of any $\mathrm{pH}$ instrument, such as the determination of dissociation constants of $\mathrm{pH}$ indicator dyes.
Uncertainties in (2) and (3) result in uncertainties of the assigned $\mathrm{pH}_{\mathrm{T}}$ values of the buffer solutions. However, it must be emphasized that effects (1)-(4) do not affect the calibration of $\mathrm{pH}$ instruments, if they include the extrapolation of calibrated parameters, e.g., the dissociation constant of $\mathrm{mCP}$ (Müller and Rehder, 2018), to pure ASW conditions. The extrapolated quantity refers to an exact definition of the total hydrogen ion concentration scale without constraints (Nemzer and Dickson, 2005; Dickson et al., 2015). Therefore, we recommend calibration of $\mathrm{pH}$ instruments in the salinity range 5-20 at the three TRIS/TRIS $\cdot \mathrm{H}^{+}$molalities reported in this study and extrapolation of the results to zero TRIS/TRIS $\cdot \mathrm{H}^{+}$molality. However, the dependence of $\mathrm{pH}_{\mathrm{T}}$ on TRIS/TRIS. $\mathrm{H}^{+}$in Equation (10) is strictly valid only for salinities 5-20 and 35 , due to the lack of experimental data at other salinities. It must also be noted that no uncertainties have been calculated for the coefficients listed in Table 2, since no uncertainties have been available for the results of DelValls and Dickson (1998). We recommend assigning uncertainties to $\mathrm{pH}_{\mathrm{T}}$ values corresponding to those given Table S6 if Equation (10) is used to calculate $\mathrm{pH}_{\mathrm{T}}$ values.

\section{Recommendations for the Preparation of TRIS Buffer Solutions}

To replicate the TRIS buffer solutions characterized in this study, we recommend production of stock solutions for the salt components of the ASW matrix. The impact of salt impurities on buffer $\mathrm{pH}_{\mathrm{T}}$ has not yet been systematically studied. Therefore, we recommend using salts of the highest purity grade, although the contribution of ASW composition to the measurement uncertainty budget is assumed to be small. The stock solution of $\mathrm{HCl}$ should be titrated against the TRIS stock solution with potentiometric or colorimetric (e.g., methyl red) endpoint detection. This ensures an exact equimolal TRIS:TRIS $\cdot \mathrm{H}^{+}$ratio, which is essential for reproducing the correct $\mathrm{pH}_{\mathrm{T}}$ value. Finally, all TRIS containing solutions should be handled so as to avoid uptake of atmospheric $\mathrm{CO}_{2}$. Ideally, the headspace of the containers should be flushed with humidified argon.

\section{Solution Composition Concept and Relevance to Natural Waters}

Alternative strategies for the solution composition applied in this study would result in pronounced changes in cation ratios at low salinity (Figure 1). Based on current knowledge it is impossible to quantify the effect of such changes of cation ratios on TRIS buffer $\mathrm{pH}_{\mathrm{T}}$, because information is lacking on the sensitivity of the TRIS. $\mathrm{H}^{+}$dissociation constant on the ionic composition of the matrix. As a future experimental approach to this open question it would be informative to perform electrochemical $\mathrm{pH}_{\mathrm{T}}$ measurement of TRIS buffered solutions in variable ASW matrices.

Characterized buffer solutions in various ASW matrices would enable studies of the impact of solution composition on the measurement signals of other $\mathrm{pH}$ instruments, including the dissociation behavior of $\mathrm{mCP}$. Such experiments could shed light on the ultimate question of how representative $\mathrm{pH}_{\mathrm{T}}$ measurements are for various natural brackish and 
freshwaters that differ in ionic composition (Feistel et al., 2010). Currently, it remains impossible to estimate the uncertainty of $\mathrm{pH}$ measurements arising from differences in the ionic composition of natural brackish water samples and the simplified composition of buffer solutions prepared in ASW matrix based on experimental data. A more detailed discussion of this issue is given in "Metrology for $\mathrm{pH}$ Measurements in Brackish WatersPart 2: Experimental Characterization of Purified meta-Cresol Purple for Spectrophotometric $\mathrm{pH}_{\mathrm{T}}$ Measurements" by Müller and Rehder (2018).

\section{CONCLUSION}

This study extends the characterization of TRIS buffer solutions by Harned cell measurements to brackish waters and provides a consistent $\mathrm{pH}_{\mathrm{T}}$ model for the salinity range 5-40. It is emphasized that minor assumptions and uncertainties remain in the $\mathrm{pH}_{\mathrm{T}}$ assignment and restrict the accuracy of all currently available TRIS buffer characterizations. However, these limitations do not affect the calibration of other $\mathrm{pH}$ instruments, if calibration results are extrapolated to zero buffer molality, which is especially important at low salinities. This study provides the required characterization of buffer solutions with variable TRIS molality in the salinity range 5-20. Measurements with $\mathrm{pH}$ instruments that have been calibrated against the buffer concentration represent currently the only access to the total hydrogen ion concentration without constraints.

\section{DATA AVAILABILITY STATEMENT}

All datasets [GENERATED/ANALYZED] for this study are included in the manuscript and the supplementary files.

\section{AUTHOR CONTRIBUTIONS}

JM: contributed to the research idea and plan, participated in the characterization of chemicals used, analyzed and interpreted the results and is first main author (shared authorship with FB) of

\section{REFERENCES}

Bates, R. G., and Hetzer, H. B. (1961). Dissociation constant of the protonated acid form of 2-amino-(hydroxymethyl)-1,3-propanediol [trishydroxymethyl)aminomethane] and related thermodynamic quantities from 0 to $50^{\circ}$. J. Phys. Chem. 65, 667-671. doi: 10.1021/j100822a017

Buck, R. P., Rondinini, S., Covington, A. K., Baucke, F. G. K., Brett, C. M. A., Camoes, M. F., et al. (2002). Measurement of pH. Definition, standards, and procedures (IUPAC recommendations 2002). Pure Appl. Chem. 74, 2169-2200. doi: 10.1351/pac200274112169

Byrne, R. H., Mecking, S., Feely, R. A., and Liu, X. (2010). Direct observations of basin-wide acidification of the North Pacific Ocean. Geophys. Res. Lett. 37:L0260. doi: 10.1029/2009GL040999

Clayton, T. D., and Byrne, R. H. (1993). Spectrophotometric seawater pH measurements - total hydrogen-ion concentration scale calibration of $\mathrm{m}$ cresol purple and at-sea results. Deep Sea Res. Part I Oceanogr. Res. Pap. 40, 2115-2129. doi: 10.1016/0967-0637(93)90048-8

DelValls, T. A., and Dickson, A. G. (1998). The pH of buffers based on 2amino-2-hydroxymethyl-1,3-propanediol ('tris') in synthetic sea water. Deep the manuscript; FB: contributed to the research plan, analyzed and interpreted the measurement results and is the second main author (shared authorship with JM) of the manuscript; BS: contributed to the research plan, performed the measurements and revised the manuscript; SS: contributed to the research plan, analyzed and interpreted the measurement results and revised the manuscript; DT: contributed in performing the research activities, in the interpretation of the results and revision of the manuscript; $\mathrm{AD}$ : contributed to the research plan, interpreted the results and revised the manuscript; GR: contributed to the research plan and revised the manuscript.

\section{FUNDING}

AD was supported by the US National Science Foundation, Grant No. OCE-1657799. Physikalisch-Technische Bundesanstalt (PTB). The research leading to this manuscript has received funding from BONUS, the joint Baltic Sea research and development program (Art 185), funded jointly from the European Union's Seventh Program for research, technological development and demonstration and from the German Federal Ministry of Education and Research through Grant No. 03F0689A (BONUS PINBAL).

\section{ACKNOWLEDGMENTS}

We acknowledge the Swiss Federal Institute of Metrology (METAS) for providing characterized salts. The quality of this paper gained from scientific discussions with Bernd Schneider, Robert H. Byrne, Kenneth W. Pratt, Regina Easley, and Michael DeGrandpre. We thank Franko Schmähling for valuable recommendations concerning appropriate fitting procedures.

\section{SUPPLEMENTARY MATERIAL}

The Supplementary Material for this article can be found online at: https://www.frontiersin.org/articles/10.3389/fmars. 2018.00176/full\#supplementary-material

Sea Res. Part I Oceanogr. Res. Pap. 45, 1541-1554. doi: 10.1016/S0967-0637(98) 00019-3

Dickson, A. G. (1990). Standard potential of the reaction: $\mathrm{AgCl}(\mathrm{s})+$ $1 / 2 \mathrm{H}_{2}(\mathrm{~g})=\mathrm{Ag}(\mathrm{s})+\mathrm{HCl}(\mathrm{aq})$, and the standard acidity constant of the ion $\mathrm{HSO}_{4}^{-}$in synthetic sea water from 273.15 to $318.15 \mathrm{~K}$. J. Chem. Thermodynamics 22, 113-127. doi: 10.1016/0021-9614 90074-Z

Dickson, A. G., Camões, M. F., Spitzer, P., Fisicaro, P., Stoica, D., Pawlowicz, R., et al. (2015). Metrological challenges for measurements of key climatological observables. Part 3: seawater pH. Metrologica 53, R26-R39. doi: 10.1088/0026-1394/53/1/R26

Doney, S. C., Fabry, V. J., Feely, R. A., and Kleypas, J. A. (2009). Ocean acidification: the other $\mathrm{CO}_{2}$ problem. Ann. Rev. Mar. Sci. 1, 169-192. doi: 10.1146/annurev.marine.010908.163834

Feistel, R., Weinreben, S., Wolf, H., Seitz, S., Spitzer, P., Adel, B., et al. (2010). Density and absolute salinity of the Baltic Sea 2006-2009. Ocean Sci. 6, 3-24. doi: 10.5194/os-6-3-2010

Gallego-Urrea, J. A., and Turner, D. R. (2017). Determination of $\mathrm{pH}$ in estuarine and brackish waters: Pitzer parameters for Tris buffers and 
dissociation constants for $m$-cresol purple at 298.15 K. Mar. Chem. 195, 84-89. doi: 10.1016/j.marchem.2017.07.004

Hills, G. J., and Ives, D. J. G. (1951). 69. The hydrogen-calomel cell. Part I. The hydrogen electrode. J. Chem. Soc. 318, 305-310. doi: 10.1039/JR9510000305

Hofmann, G. E., Smith, J. E., Johnson, K. S., Send, U., Levin, L. A., Micheli, F., et al. (2011). High-frequency dynamics of ocean $\mathrm{pH}$ : a multi-ecosystem comparison. PLoS ONE 6:e28983. doi: 10.1371/journal.pone.0028983

Harned, H. S., and Owen, B. B. (1958). The Physical Chemistry of Electrolytic Solutions, Chap. 14. New York, NY: Reinhold.

ISO/IEC (2008). Guide to the expression of uncertainty in measurement (2008), Guide 98-3, Geneva, Switzerland

Kulinski, K., Schneider, B., Hammer, K., Machulik, U., and Schulz-Bull, D. (2014). The influence of dissolved organic matter on the acid-base system of the Baltic Sea. J. Mar. Syst.. 132, 106-115. doi: 10.1016/j.jmarsys.2014.01.011

Le Quéré, C., Andrew, R. M., Canadell, J. G., Sitch, S., Korsbakken, J. I., Peters, G. P., et al (2016). Global carbon budget 2016. Earth Syst. Sci. Data 8, 605-649. doi: 10.5194/essd-8-605-2016

Liu, X., Patsavas, M. C., and Byrne, R. H. (2011). Purification and characterization of meta-cresol purple for spectrophotometric seawater $\mathrm{pH}$ measurements. Environ. Sci. Technol.. 45, 4862-4868. doi: 10.1021/es200665d

Loucaides, S., Rèrolle, V. M. C., Papadimitriou, S., Kennedy, H., Mowlem, M. C., Dickson, A. G., et al. (2017). Characterization of meta-Cresol Purple for spectrophotometric $\mathrm{pH}$ measurements in saline and hypersaline media at sub-zero temperatures. Sci. Rep. 7, 1-11. doi: 10.1038/s41598-017-02624-0

Martz, T. R., Connery, J. G., and Johnson, K. S. (2010). Testing the Honeywell Durafet for seawater $\mathrm{pH}$ applications. Limnol. Oceanogr. Methods 8, 172-184. doi: 10.4319/lom.2010.8.172

Meija, J., Coplen, T. B., Berglund, M., Brand, W. A., De Bièvre, P., Gröning, M., et al. (2016). Atomic weights of the elements 2013 (IUPAC Technical Report). Pure Appl. Chem. 88, 265-291. doi: 10.1515/pac-2015-0305

Mosley, L. M., Husheer, S. L. G., and Hunter, K. A. (2004). Spectrophotometric pH measurement in estuaries using thymol blue and $\mathrm{m}$-cresol purple. Mar. Chem. 91, 175-186. doi: 10.1016/j.marchem.2004.06.008

Müller, J. D., and Rehder, G. (2018) Metrology for pH measurements in brackish waters - part 2: experimental characterization of purified m-Cresol
Purple for spectrophotometric pHT measurements. Front. Mar. Sci. 5:177. doi: 10.3389/fmars.2018.00177

Müller, J. D., Schneider, B., Aßmann, S., and Rehder, G. (2018). Spectrophotometric $\mathrm{pH}$ measurements in the presence of dissolved organic matter and hydrogen sulfide. Limnol. Oceanogr. Methods 16, 68-82. doi: 10.1002/lom 3.10227

Müller, J. D., Schneider, B., and Rehder, G. (2016). Long-term alkalinity trends in the Baltic Sea and their implications for $\mathrm{CO}_{2}$-induced acidification. Limnol. Oceanogr. 61, 1984-2002. doi: 10.1002/lno.10349

Nemzer, B. V., and Dickson, A. G. (2005). The stability and reproducibility of Tris buffers in synthetic seawater. Mar. Chem. 96, 237-242. doi: 10.1016/j.marchem.2005.01.004

Papadimitriou, S., Loucaides, S., Rérolle, V., Achterberg, E. P., Dickson, A. G., Mowlem, M., et al. (2016). The measurement of $\mathrm{pH}$ in saline and hypersaline media at sub-zero temperatures: characterization of Tris buffers. Mar. Chem. 184, 11-20. doi: 10.1016/j.marchem.2016.06.002

Pratt, K. (2014). Measurement of $\mathrm{pH}_{\mathrm{T}}$ values of Tris buffers in artificial seawater at varying mole ratios of Tris:Tris.HCl. Mar. Chem. 162, 89-95. doi: 10.1016/j.marchem.2014.03.003

R Core Team (2014). R: A Language and Environment for Statistical Computing. Available online at: http://www.r-project.org/

Waters, J. F., and Millero, F. J. (2013). The free proton concentration scale for seawater pH. Mar. Chem. 149, 8-22. doi: 10.1016/j.marchem.2012.11.003

Conflict of Interest Statement: The authors declare that the research was conducted in the absence of any commercial or financial relationships that could be construed as a potential conflict of interest.

Copyright (C) 2018 Müller, Bastkowski, Sander, Seitz, Turner, Dickson and Rehder. This is an open-access article distributed under the terms of the Creative Commons Attribution License (CC BY). The use, distribution or reproduction in other forums is permitted, provided the original author(s) and the copyright owner(s) are credited and that the original publication in this journal is cited, in accordance with accepted academic practice. No use, distribution or reproduction is permitted which does not comply with these terms. 